\title{
Bone Spectrometry
}

National Cancer Institute

\section{Source}

National Cancer Institute. Bone Spectrometry. NCI Thesaurus. Code C38039.

Spectrometry used to determine aspects of bone composition. 